\title{
Simulasi Dampak Penghalang pada Gelombang Tsunami Menggunakan Persamaan Air Dangkal dengan Metode Beda Hingga
}

\author{
Ahmad Zaenal Arifin ${ }^{*}$ \\ ${ }_{1}$ Program Studi Matematika, Fakultas MIPA, Universitas PGRI Ronggolawe, \\ Jl. Manunggal No. 61 Tuban 62381, Jawa Timur, Indonesia \\ *Penulis Korespondensi.Email:az_arifin@unirow.ac.id
}

\section{ABSTRAK}

Tsunami menjadi salah satu bencana alam yang paling berbahaya di daerah sekitar pesisir. Dampak dari gelombang tsunami menyebabkan kerugian yang besar bagi manusia, adanya banyak korban jiwa dan juga besarnya kerugian dalam bidang ekonomi. Artikel ini menunjukkan simulasi dengan pendekatan numerik metode beda hingga untuk menunjukkan dampak keberadan barrier sebagai penghalang gelombang tsunami. Gelombang tsunami dapat direpresntasikan dengan menggunakan persamaan air dangkal. Persamaan air dangkal secara umum digunakan dalam menggambarkan masalah fluida yang didasari oleh konservasi fisik dan juga dapat digunakan untuk menggambarkan terjadinya gelombang tsunami. Persamaan air dangkal berbentuk persamaan diferensial parsial sehingga dapat diselesaikan menggunakan metode beda hingga. Hasil simulasi persamaan air dangkal menunjukan bahwa persamaan air dangkal dapat merepresentasikan gelombang tsunami dengan konstruksi penghalang dan diketahui bahwa pembangunan sebuah penghalang dapat memecah gelombang tsunami dan dapat mengurangi kekuatan gelombang.

\section{Kata Kunci:}

Tsunami; Persamaan Air Dangkal; Metode Beda Hingga

\section{ABSTRACT}

One of the most dangerous natural disasters in the coastal area is Tsunami. The tsunami waves impact caused considerable losses to humans, many casualties, and significant losses in the economic field. This article shows a simulation using the numerical approach of finite difference methods to deliver the barrier's impact is a tsunami wave barrier. Tsunami waves can be represented using the shallow water equation. The shallow water equation is generally used to describe fluid problems based on physical conservation and define tsunami waves. The shallow water equation is in the form of a partial differential equation to be solved using the finite difference method. The shallow water equation's simulation results show that the shallow water equation can represent a tsunami wave with a barrier construction. It is known that the construction of a barrier can break the tsunami waves and reduce the strength of the waves.

\section{Keywords:}

Tsunami; Shallow Water Equation; Finite-Different Method

\section{Format Sitasi:}

A.Z. Arifin, "Simulasi Dampak Penghalang pada Gelombang Tsunami Menggunakan Persamaan Air Dangkal dengan Metode Beda Hingga," Jambura J. Math., vol. 3, no. 2, pp. 93102,2021 


\section{Pendahuluan}

Indonesia sebagai negara yang dilalui lempeng besar dunia yaitu lempeng Eurasia, Indoaustralia dan Pasifik memiliki potensi bencana alam yang tinggi [1], [2]. Lempeng ini memiliki aktivitas seismik tinggi yang menyebabkan munculnya banyak bencana alam [3], [4], salah satunya adalah terjadinya gempa bumi sebagai dampak utama dari aktivitas seismik dan tsunami sebagai dampak sekunder [1], [5], [6].Tsunami menjadi salah satu bencana alam paling berbahaya di kawasan sekitar pantai [7]-[9]. Tsunami muncul sebagai akibat dari perpindahan air dalam jumlah besar akibat dari gempa bumi, letusan gunung berapi bawah laut, tanah longsor atau penyebab lain yang terjadi di atas atau di bawah dasar laut [10]. Ombak laut tidak berbahaya jika ketinggian tidak melebihi 1 meter. Namun, menjadi bencana bila energi gelombang terkonsentrasi dengan besar dan panjang gelombang lebih besar dari kedalaman laut. Ketika gelombang memasuki zona perairan dangkal, kecepatan gelombang di tepi pantai menurun tajam dan tinggi gelombang meningkat sepuluh kali lipat [7]-[9].

Dampak gelombang tsunami tersebut menimbulkan kerugian yang sangat besar bagi manusia, korban yang sangat besar jumlahnya dan kerugian di bidang ekonomi. Wilayah pesisir yang terkena gelombang tsunami membutuhkan waktu yang lama dan sumber daya ekonomi yang mahal untuk memulihkannya [11]. Tercatat dalam dua dekade terakhir, telah terjadi 12 tsunami dari 252 gempa bumi dengan total kerugian 79,5 triliun rupiah [12]. Di Indonesia orientasi dalam meminimalkan risiko bencana lebih mengarah pada penanganan darurat atau kuratif dan belum mengarah pada aspek preventif [13]. Oleh karena itu, diperlukan peningkatan pemahaman tentang faktor fisik, keteknikan dan sosial terkait dengan pelaksanaan mitigasi bencana.

Bahaya gelombang tsunami sangat tidak terduga, tiba-tiba dan luar biasa sehingga hampir tidak mungkin untuk dihindari. Pada tahun 2013, Suppasri [7] melakukan penelitian terkait kinerja mitigasi bencana pada saat terjadinya tsunami di Jepang pada tahun 2011. Hasil dari penelitiannya mengatakan bahwa diperlukan adanya bangunan penahan gelombang tsunami. Sedangkan pada tahun 2016, Boshenyatov dan Zhiltsov melakukan penelitian terkait efektifitas pembangunan penghalang bawah air [9]. Hasil penelitiannya menyatakan bahwa pembangunan penghalang bawah laut yang berjarak memiliki dampak yang signifikan untuk memecah gelombang [9]. Selain itu, negara lain yang mengalami bencana serupa telah melakukan beberapa studi terkait dalam meminimalkan risiko bencana dengan membangun penghalang tsunami menggunakan metode penelitian analitik dan pendekatan pemodelan numerik [11][14].

Pendekatan pemodelan numerik untuk aliran fluida sudah cukup banyak, dua diantaranya yang paling populer adalah persamaan Navier Stoke [15]-[17] dan Persamaan Air Dangkal [18]-[21]. Persamaan Navier Stoke lebih banyak digunakan untuk pemodelan banjir [22][23] dan longsor [24]-[26]. Adapun persamaan air dangkal digunakan untuk membuat simulasi gelombang [15]-[17]. Untuk persamaan air dangkal dapat diselesaikan menggunakan metode beda hingga. Metode yang digunakan untuk menyelesaikan persamaan diferensial parsial adalah metode beda hingga dengan menggunakan pendekatan deret taylor [27][28]. Metode beda hingga menghasilkan solusi yang memuaskan pada banyak kasus numerik [29][30]. Selain itu, metode beda hingga juga pernah didigabungkan dengan metode Smooth Particle Hydrodynamic $(\mathrm{SPH})$ oleh Asai [31], dan hasilnya performa metode beda hingga dapat memvalidasi bentuk gelombang tsunami melalui pembuat gelombang virtual. Oleh karena itu, 
persamaan air dangkal berbentuk persamaan diferensial parsial sangat mungkin untuk diselesaikan dengan menggunakan metode beda hingga

Pada makalah ini, penghalang yang akan dibangun menggunakan simulasi adalah penghalang yang muncul pada permukaan air laut. Penghalang tersebut diharapkan mampu mengurangi kekuatan gelombang dan juga memecah gelombang tsunami sehingga gelombang tsunami yang awalnya memiliki kekuatan yang besar menjadi teredam.

\section{Metode}

\subsection{Metode Beda Hingga}

Metode yang digunakan dalam menyelesaikan Persamaan Diferensial Parsial (PDP) yang dapat digunakan untuk mendekati deret Taylor [27][28]. Persamaan diferensial adalah estimasi nilai $\delta$ pada titik-titik perhitungan $U_{1,1}, U_{1,2}, \ldots, U_{i, j}$, untuk estimasi dapat dilakukan dengan mensubtitusi turunan parsial persamaan diferensial menggunakan perkiraan perbedaan hingga [32].

Turunan pertama dapat dihitung menggunakan pendekatan perbedaan maju dengam $\frac{\partial u}{\partial x}, \frac{\partial u}{\partial y}$ dan $\frac{\partial u}{\partial t}$ dari persamaan diferensial berdasarkan deret Taylor yang dapat dituliskan seperti di bawah ini:

$$
\begin{aligned}
& \frac{\partial u(x, y, t)}{\partial x}=\frac{1}{\Delta x}(u(x+\Delta x, y, t))-u(x, y, t) \\
& \left.\frac{\partial u(x, y, t)}{\partial y}=\frac{1}{\Delta y}(u(x, y+\Delta y, t))-u(x, y, t)\right) \\
& \left.\frac{\partial u(x, y, t)}{\partial t}=\frac{1}{\Delta t}(u(x, y, t+\Delta t))-u(x, y, t)\right) .
\end{aligned}
$$

Jika pendekatannya mundur, turunan pertama dari $\frac{\partial u}{\partial x}, \frac{\partial u}{\partial y}$ dan $\frac{\partial u}{\partial t}$ dapat dituliskan seperti dibawah ini:

$$
\begin{aligned}
& \left.\frac{\partial u(x, y, t)}{\partial x}=\frac{1}{\Delta x}(u(x+\Delta x, y, t))-u(x-\Delta x, y, t)\right) \\
& \left.\frac{\partial u(x, y, t)}{\partial y}=\frac{1}{\Delta y}(u(x+\Delta x, y, t))-u(x, y-\Delta y, t)\right) \\
& \left.\frac{\partial u(x, y, t)}{\partial t}=\frac{1}{\Delta t}(u(x+\Delta x, y, t))-u(x, y, t-\Delta t)\right) .
\end{aligned}
$$

Turunan kedua dengan menggunakan beda pusat diperoleh:

$$
\begin{aligned}
\frac{\partial^{2} u}{\partial x^{2}} & =\frac{1}{\Delta x^{2}}(u(x+\Delta x, y, t)-2 u(x, y, t)-u(x-\Delta x, y, t)) \\
\frac{\partial^{2} u}{\partial y^{2}} & =\frac{1}{\Delta y^{2}}(u(x, y+\Delta y, t)-2 u(x, y, t)-u(x, y-\Delta y, t)) \\
\frac{\partial^{2} u}{\partial t^{2}} & =\frac{1}{\Delta t^{2}}(u(x, y, t+\Delta t)-2 u(x, y, t)-u(x, y, t-\Delta t)) .
\end{aligned}
$$


Titik diskrit $x$ dan $y$ direpresentasikan dengan subskrip $i$ dan $j$, sedangkan titik diskrit $t$ direpresentasikan oleh superskrip $n$, sehingga persamaan (7)-(9) dapat ditulis:

$$
\begin{aligned}
\frac{\partial^{2} u}{\partial x^{2}} & =\frac{\bigcup_{i+1, j}^{n}-2 \bigcup_{i, j}^{n}+U_{i-1, j}^{n}}{\partial x^{2}} \\
\frac{\partial^{2} u}{\partial y^{2}} & =\frac{\bigcup_{i 1, j+1}^{n}-2 \bigcup_{i, j}^{n}+U_{i-1, j}^{n}}{\partial y^{2}} \\
\frac{\partial^{2} u}{\partial t^{2}} & =\frac{\bigcup_{i, j}^{n+1}-2 \bigcup_{i, j}^{n}+U_{i-1, j}^{n-1}}{\partial t^{2}} .
\end{aligned}
$$

\subsection{Shallow Water Equation (SWE)}

Shallow water equation umumnya digunakan untuk memodelkan gelombang permukaan air yang dipengaruhi oleh gravitasi, seperti aliran gelombang di permukaan pantai, danau, sungai, atau pada domain yang lebih kecil, misalnya permukaan air di bak mandi [33][34]:

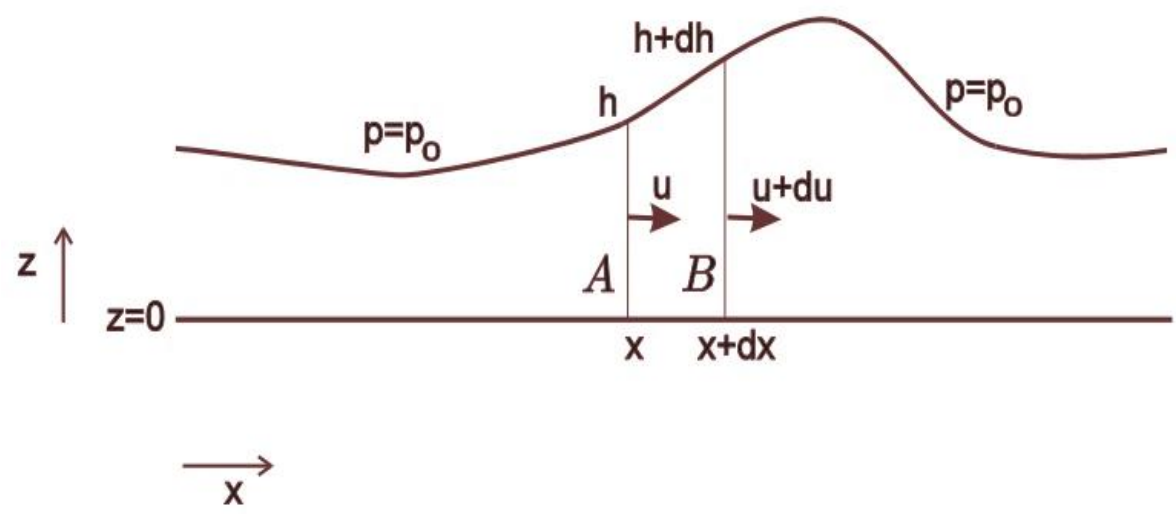

Gambar 1. Ilustrasi Shallow Water Equation [32]

SWE akan berlaku jika panjang gelombang lebih besar dari pada kedalaman.

$$
\begin{aligned}
& \frac{\partial h}{\partial t}+\frac{\partial(u h)}{\partial x}=0 \\
& \frac{\partial(u h)}{\partial t}+\frac{\partial\left(h u^{2}+\frac{1}{2} g h^{2}\right)}{\partial x}=0 .
\end{aligned}
$$

Sedangkan pada soal dua dimensi, SWE dikemukakan sebagai berikut,

$$
\begin{aligned}
& \frac{\partial h}{\partial t}+\frac{\partial(u h)}{\partial x}+\frac{\partial(h v)}{\partial y}=0 \\
& \frac{\partial(h u)}{\partial t}+\frac{\partial\left(h u^{2}+\frac{1}{2} g h^{2}\right)}{\partial x}+\frac{\partial(h u y)}{\partial y}=0 \\
& \frac{\partial(h u)}{\partial t}+\frac{\partial(h u v)}{\partial x}+\frac{\partial\left(h u^{2}+\frac{1}{2} g h^{2}\right)}{\partial y}=0
\end{aligned}
$$


dengan $g$ adalah konstanta gravitasi bumi, $\mathrm{h}$ adalah tinggi permukaan laut dimana $(u, v)$ adalah vektor kecepatan aliran air, dan hu dan hv adalah momentum dalam dua arah [33][34].

\section{Hasil dan Pembahasan}

\subsection{Analisis Gelombang Tsunami}

Shallow water equation untuk mensimulasikan pergerakan gelombang tsunami yang memiliki hambatan dengan menggunakan metode beda hingga. Shallow water equation berasal dari persamaan kekekalan massa dan kekekalan momentum linier (persamaan Navier-Stokes).

Persamaan massa dalam volume didefinisikan sebagai berikut,

$$
\begin{aligned}
\frac{\partial m}{\partial t} & =\rho u(x) h(x)-\rho u(x+d x) h(x+d x) \\
& =-\rho \frac{\partial(u h)}{\partial x} d x .
\end{aligned}
$$

Dengan asumsi $m=\rho h d x$ diperoleh

$$
h_{t}+(u h)_{x}=0
$$

Berdasarkan hukum Newton tentang gerak yang diterapkan pada volume didefinisikan sebagai

$$
F=m \frac{d u}{d t}=-\rho g h \frac{\partial h}{\partial x} d x
$$

Dengan menerapkan $m=\rho h d x$ diperoleh,

$$
\frac{d u}{d t}=-g \frac{\partial h}{\partial x}
$$

Kemudian aturan rantai diterapkan hingga $\frac{d}{d t}$ diperoleh,

$$
\frac{d u}{d t}=\frac{\partial u}{\partial t}+u \frac{\partial u}{\partial x}
$$

sehingga persamaan (16) dinyatakan dengan

$$
(h u)_{t}+\left(h u^{2}+\frac{1}{2} g h^{2}\right)_{x}=0
$$

Untuk masalah yang diadopsi dalam penelitian ini, persamaan air dangkal tidak memiliki gaya coriolis. 
Simulasi Dampak Penghalang pada Gelombang Tsunami Menggunakan Persamaan Air ...

\subsection{Diskritisasi Waktu Gelombang Tsunami}

Berdasarkan persamaan air dangkal yang didekati dengan metode beda hingga, persamaan (4), (5) dan (6) disubstitusikan ke persamaan (16) dan (17), sehingga diperoleh

$$
\begin{array}{rl}
u_{i, j}^{n+1}= & \frac{u_{i+1, j}^{n}+}{} u_{i-1, j}^{n}+u_{i, j+1}^{n}+u_{i, j-1}^{n} \\
4 & 0.5 \frac{d t}{d x}\left(\frac{\left(u_{i+1, j}^{n}\right)^{2}}{2}-\frac{\left(u_{i-1, j}^{n}\right)^{2}}{2}\right) \\
& -0.5 \frac{d t}{d y} v_{i, j}^{n}\left(u_{i, j+1}^{n}-u(i, j-1, n)\right)-0.5 g \frac{d t}{d x}\left(h_{i+1, j}^{n}-h_{i-1, j}^{n}\right) \\
v_{i, j}^{n+1}= & \frac{v_{i+1, j}^{n}+v_{i-1, j}^{n}+v_{i, j+1}^{n}+v_{i, j-1}^{n}}{4}-0.5 \frac{d t}{d y}\left(\frac{\left(v_{i, j+1}^{n}\right)^{2}}{2}-\frac{\left(v_{i, j-1}^{n}\right)^{2}}{2}\right) \\
& -0.5 \frac{d t}{d x} u_{i, j}^{n}\left(v_{i+1, j}^{n}-v_{i-1, j}^{n}\right)-0.5 g \frac{d t}{d y}\left(h_{i, j}^{n}-h_{i, j}^{n}\right) \\
h_{i, j}^{n+1}=\left(\frac{h_{i+1}^{n}+}{+} h_{i-1, j}^{n}+h_{i, j+1}^{n}+h_{i, j-1}^{n}\right)-0.5 \frac{d t}{4 x} u_{i, j}^{n}\left(\left(h_{i+1, j}^{n}-b_{i+1, j}\right)-\left(h_{i-1}^{n}-b_{i-1, j}\right)\right) \\
\quad-0.5 \frac{d t}{d y} v_{i, j}^{n}\left(\left(h_{i, j+1}^{n}-b_{i, j+1}\right)-\left(h_{i, j-1}^{n}-b_{i, j-1}\right)\right) \\
\quad-0.5 \frac{d t}{d x}\left(h_{i, j}^{n}-b_{i, j}\right)\left(u_{i+1, j}^{n}-u_{i-1}^{n}\right)-0.5 \frac{d t}{d y}\left(h_{i, j}^{n}-b_{i, j}\right)\left(v_{i, j+1}^{n}-v_{i, j-1}^{n}\right)
\end{array}
$$

dengan syarat batas [35]:

$$
\begin{aligned}
& u(1, i, n+1)=2.5 u(2, i, n+1)-2 u(3, i, n+1)+0.5 u(4, i, n+1) \\
& v(1, i, n+1)=2.5 v(2, i, n+1)-2 v(3, i, n+1)+0.5 v(4, i, n+1) \\
& h(1, i, n+1)=2.5 h(2, i, n+1)-2 h(3, i, n+1)+0.5 h(4, i, n+1)
\end{aligned}
$$

dengan $u$ kecepatan arah $x, v$ adalah kecepatan arah $y$, dan $h$ adalah ketinggian awal (normal) gelombang laut. Simulasi awal pembentukan gelombang $(t=1)$ ditunjukkan pada Gambar 2. Parameter yang digunakan gravitasi $(g=9,81 \mathrm{~m} / \mathrm{s})$, kecepatan awal arah $x\left(u_{0}=0\right)$, kecepatan awal arah $y\left(v_{0}=0 \mathrm{~m} / \mathrm{s}\right)$, dasar laut $(b=0 \mathrm{~m})$, dan ketinggian awal $\left(h_{0}=5030 \mathrm{~m}\right)$.

Pada penelitian ini, bentuk dan ketinggian penghalang diabaikan sebagai Batasan penelitian. Diasumsikan saat tsunami pertama kali muncul ke permukaan setelah terjadi pergeseran lempeng bumi di bawah laut. Sehingga kemunculan pertamanya ke permukaan akan sangat besar pada titik awal kemunculannya kemudian bergerak menuju daratan.

Pada Gambar 2 ketinggian gelombang tsunami nampak memiliki ketinggian yang melebihi ketinggian penghalang yaitu 8 meter di atas permukaan laut. Kemudian pada waktu berikutnya, gelombang tsunami akan berpindah-pindah, salah satunya menuju perairan dangkal yang telah dibangun pembatas. Berdasarkan hasil simulasi, gelombang tsunami akan mengalami benturan dengan penghalang dalam waktu 35 detik sejak tsunami muncul. 


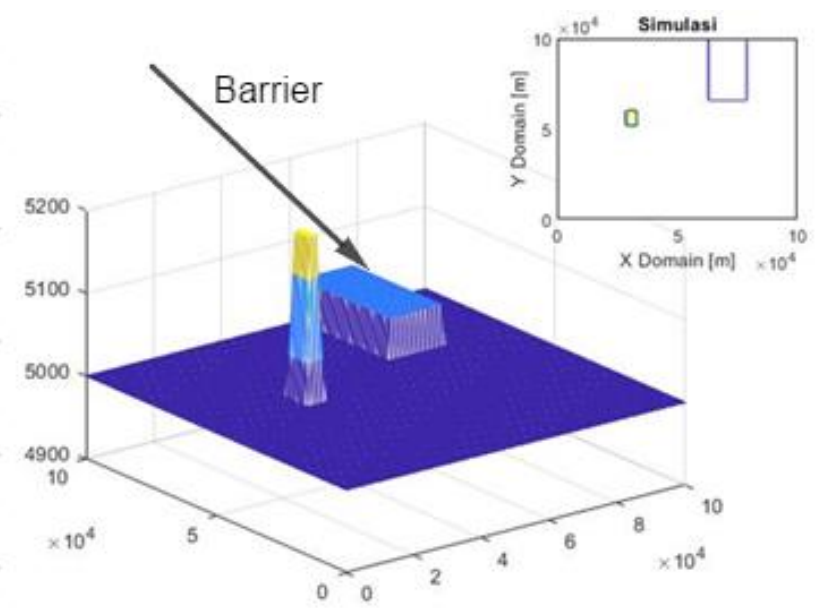

Gambar 2. Simulasi gelombang Tsunami saat $t=35$ detik

Tumbukan gelombang dengan penghalang ditunjukkan pada Gambar 3. Akibat tumbukan dengan penghalang gelombang tsunami itu pecah dan dapat ditekan. Redaman oleh penghalang berarti daerah di belakang penghalang tidak terkena tsunami secara langsung. Gelombang tsunami menghantam daerah di belakang pembatas akibat dampak tsunami dari daerah yang tidak terlindung oleh pembatas. Dampaknya tidak setinggi gelombang tsunami tanpa pembatas.

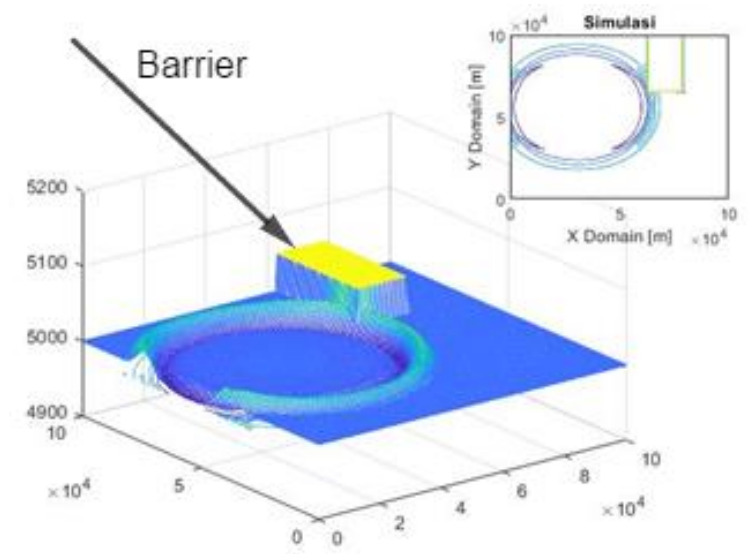

Gambar 3. Simulasi gelombag Tsunami saat $t=40$ detik

Gambar 4 menunjukkan kondisi gelombang tsunami di balik penghalang teredam.

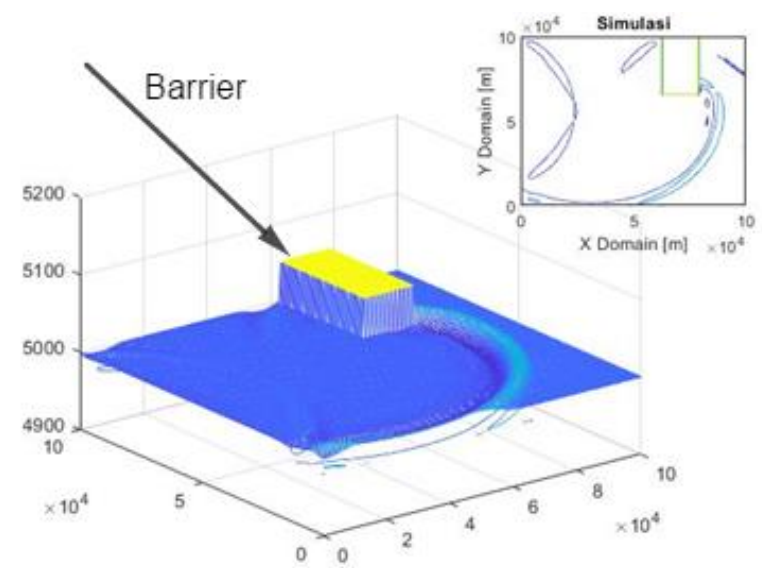

Gambar 4. Simulasi gelombang Tsunami saat $t=65$ detik 
Kondisi peredaman pada Gambar 4 terjadi pada waktu $t=65$ detik. Proses peredaman dilakukan secara terus menerus oleh pembatas yang telah terbentuk, hingga gelombang kembali tenang, sebagaimana ditunjukkan pada Gambar 5.

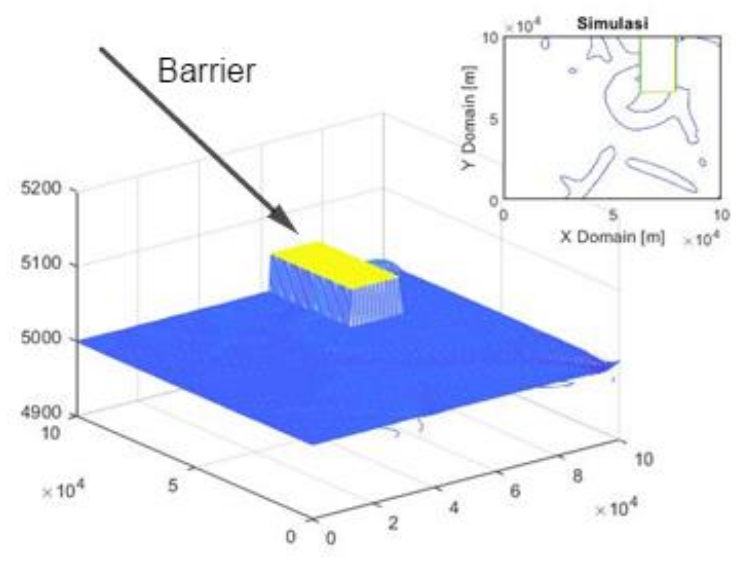

Gambar 5. Simulasi Gelombag Tsunami saat $t=100$ detik

\section{Kesimpulan}

Solusi numerik dan simulasi yang telah dilakukan pada persamaan air dangkal dapat merepresentasikan gelombang tsunami secara jelas dan dengan adanya penghalang, gelombang Tsunami dapat dipecah seperti yang terjadi pada saat $t=0$ detik yang merupakan awal mula terjadinya gelombang Tsunami sampai pada waktu $t=40$ detik, yang menunjukkan gelombang Tsunami menabrak penghalang. Selanjutnya pada detik ke 60, gelombang tsunami sudah mengalami pengurangan kekuatan gelombang. Hasil tersebut menunjukkan bahwa adanya penghalang sangat berpengengaruh terhadap kekuatan geombang tsunami. Dengan demikian, salah satu upaya yang dapat dilakukan untuk mengurangi dampak Tsunami adalah dengan merealisasikan pembangaunan penghalang di daerah-daerah yang berpotensi Tsunami.

\section{Ucapan Terima Kasih}

Penelitian ini mendapatkan dukungan anggaran dari Lembaga Penelitian Universitas PGRI Ronggolawe Tuban.

\section{Referensi}

[1] T. W. Wibowo, D. Mardiatno, and S. Sunarto, "Pemetaan Risiko Tsunami terhadap Bangunan secara Kuantitatif," Maj. Geogr. Indones., vol. 31, no. 2, pp. 6878, 2017.

[2] A. J. Santoso, F. K. S. Dewi, and T. A. P. Sidhi, "Natural disaster detection using wavelet and artificial neural network," in 2015 Science and Information Conference (SAI), 2015, pp. 761-764.

[3] H. Guo, "Understanding global natural disasters and the role of earth observation," Int. J. Digit. Earth, vol. 3, no. 3, pp. 221-230, 2010.

[4] H. Latief, N. T. Puspito, and F. Imamura, "Tsunami catalog and zones in Indonesia," J. Nat. Disaster Sci., vol. 22, no. 1, pp. 25-43, 2000.

[5] E. Krausmann and A. M. Cruz, "Impact of the 11 March 2011, Great East Japan 
earthquake and tsunami on the chemical industry," Nat. hazards, vol. 67, no. 2, pp. 811-828, 2013.

[6] K. D. Marano, D. J. Wald, and T. I. Allen, "Global earthquake casualties due to secondary effects: a quantitative analysis for improving rapid loss analyses," Nat. hazards, vol. 52, no. 2, pp. 319-328, 2010.

[7] A. Suppasri, N. Shuto, F. Imamura, S. Koshimura, E. Mas, and A. C. Yalciner, "Lessons learned from the 2011 Great East Japan tsunami: performance of tsunami countermeasures, coastal buildings, and tsunami evacuation in Japan," Pure Appl. Geophys., vol. 170, no. 6, pp. 993-1018, 2013.

[8] M. Esteban et al., "Awareness of coastal floods in impoverished subsiding coastal communities in Jakarta: Tsunamis, typhoon storm surges and dyke-induced tsunamis," Int. J. disaster risk Reduct., vol. 23, pp. 70-79, 2017.

[9] B. V Boshenyatov and K. N. Zhiltsov, "Simulation of the interaction of tsunami waves with underwater barriers," in AIP Conference Proceedings, 2016, vol. 1770, no. 1, p. 30088.

[10] A. Tan, A. K. Chilvery, M. Dokhanian, and S. H. Crutcher, "Tsunami Propagation Models Based on First Principles," Ed. by Gloria I. Lopez, p. 107, 2012.

[11] M. del Jesus, J. L. Lara, and I. J. Losada, "Numerical Modeling of Tsunami Waves Interaction with Porous and Impermeable Vertical Barriers," J. Appl. Math., vol. 2012, 2012.

[12] S. Gerintya, "Gempa dan Tsunami: Mitigasi Buruk, Kerugian Tinggi - Tirto.ID." https://tirto.id/gempa-dan-tsunami-mitigasi-buruk-kerugian-tinggi-c31k (accessed Feb. 20, 2021).

[13] B. N. P. Bencana, "Risiko Bencana Indonesia," Badan Nas. Penanggulangan Bencana Jakarta, 2016.

[14] A. Kurniasih, J. Marin, and R. Setyawan, "Belajar dari Simeulue: Memahami Sistem Peringatan Dini Tsunami di Indonesia," J. Geosains dan Teknol., vol. 3, no. 1, pp. 21-30, 2020.

[15] K. Hu, C. G. Mingham, and D. M. Causon, "Numerical simulation of wave overtopping of coastal structures using the non-linear shallow water equations," Coast. Eng., vol. 41, no. 4, pp. 433-465, 2000.

[16] P. Lin and P. L.-F. Liu, "Internal wave-maker for Navier-Stokes equations models," J. Waterw. port, coastal, Ocean Eng., vol. 125, no. 4, pp. 207-215, 1999.

[17] P. Higuera, J. L. Lara, and I. J. Losada, “Realistic wave generation and active wave absorption for Navier-Stokes models: Application to OpenFOAM®," Coast. Eng., vol. 71, pp. 102-118, 2013.

[18] N. Thurey, M. Muller-Fischer, S. Schirm, and M. Gross, "Real-time breaking waves for shallow water simulations," in 15th Pacific Conference on Computer Graphics and Applications (PG'07), 2007, pp. 39-46.

[19] D. Muliyati et al., "Simulation of ocean waves in coastal areas using the shallowwater equation," in Journal of Physics: Conference Series, 2019, vol. 1402, no. 7, p. 77025.

[20] P. A. Clarkson and E. L. Mansfield, "On a shallow water wave equation," Nonlinearity, vol. 7, no. 3, p. 975, 1994.

[21] Y. Zhou, "Wave breaking for a shallow water equation," Nonlinear Anal. Theory, 
Simulasi Dampak Penghalang pada Gelombang Tsunami Menggunakan Persamaan Air ...

Methods Appl., vol. 57, no. 1, pp. 137-152, 2004.

[22] H. Ozmen-Cagatay, S. Kocaman, and H. Guzel, "Investigation of dam-break flood waves in a dry channel with a hump," J. Hydro-environment Res., vol. 8, no. 3, pp. 304-315, 2014.

[23] G. Di Baldassarre, G. Schumann, P. D. Bates, J. E. Freer, and K. J. Beven, “Floodplain mapping: a critical discussion of deterministic and probabilistic approaches," Hydrol. Sci. Journal-Journal des Sci. Hydrol., vol. 55, no. 3, pp. 364376, 2010.

[24] A. M. Abdelrazek, I. Kimura, and Y. Shimizu, "Numerical simulation of a smallscale snow avalanche tests using non-Newtonian SPH model," 土木学会論文集 A2, vol. 70, no. 2, p. I_681-I_690, 2014.

[25] E. Bovet, B. Chiaia, and L. Preziosi, "A new model for snow avalanche dynamics based on non-Newtonian fluids," Meccanica, vol. 45, no. 6, pp. 753-765, 2010.

[26] D. Dutykh, C. Acary-Robert, and D. Bresch, "Mathematical Modeling of PowderSnow Avalanche Flows," Stud. Appl. Math., vol. 127, no. 1, pp. 38-66, 2011.

[27] S. D. Gedney, "Introduction to the finite-difference time-domain (FDTD) method for electromagnetics," Synth. Lect. Comput. Electromagn., vol. 6, no. 1, pp. 1-250, 2011.

[28] D. F. S. Mary and D. Lee, "Analysis of an implicit finite difference solution to an underwater wave propagation problem," J. Comput. Phys., vol. 57, no. 3, pp. 378390, 1985.

[29] J. A. Liggett and D. A. Woolhiser, "Difference solutions of the shallow-water equation," J. Eng. Mech. Div., vol. 93, no. 2, pp. 39-72, 1967.

[30] Y. Xing and C.-W. Shu, "High order finite difference WENO schemes with the exact conservation property for the shallow water equations," J. Comput. Phys., vol. 208, no. 1, pp. 206-227, 2005.

[31] M. Asai, Y. Miyagawa, N. Idris, A. Muhari, and F. Imamura, "Coupled tsunami simulations based on a $2 \mathrm{~d}$ shallow-water equation-based finite difference method and 3d incompressible smoothed particle hydrodynamics," J. Earthq. Tsunami, vol. 10, no. 05, p. 1640019, 2016.

[32] E. Kreyszig, Advanced Engineering Mathematics. United States of America: Luarie Rosatone, 2011.

[33] E. A. Karjadi, M. Badiey, J. T. Kirby, and C. Bayindir, "The effects of surface gravity waves on high-frequency acoustic propagation in shallow water," IEEE J. Ocean. Eng., vol. 37, no. 1, pp. 112-121, 2011.

[34] S. Elgar and R. T. Guza, "Shoaling gravity waves: Comparisons between field observations, linear theory, and a nonlinear model," J. Fluid Mech., vol. 158, pp. 47-70, 1985.

[35] F. Alcrudo and P. Garcia-Navarro, "A high-resolution Godunov-type scheme infinite volumes for the 2D shallow-water equations," Int. J. Numer. Methods Fluids, vol. 16, no. 6, pp. 489-505, 1993.

This article is an open-access article distributed under the terms and conditions of the Creative Commons Attribution-NonCommercial 4.0 International License. Editorial of JJoM: Department of Mathematics, Universitas Negeri Gorontalo, Jln. Prof. Dr. Ing. B.J. Habibie, Moutong, Tilongkabila, Kabupaten Bone Bolango, Provinsi Gorontalo 96119, Indonesia. 